\title{
OS PADRÕES ÉTICOS DA PROPAGANDA NA AMÉRICA LATINA
}

Maria Cecília Coutinho de Arruda
E-mail carruda@eaesp.fgvsp.br
Professora do Departamento de Mercadologia e Coordenadora
do CENE (Centro de Estudos de Ética nos Negócios) da EAESP/FGV.

Adriana Uono

Graduanda em Administração de Empresas na EAESP/FGV.

Juliano Allegrini

Graduando em Administração de Empresas na EAESP/FGV.

RESUMO: O presente estudo busca compreender a percepção sobre o conceito de ética, a performance ética e a responsabilidade social na atividade de propaganda na América Latina. Foram definidos padrões e diretrizes que norteiam a ação de um publicitário e, em função deles, foram analisadas tendências e intuiçōes dos profissionais em nove paises: Argentina, Brasil, Chile, Costa Rica, Guatemala, Honduras, México, Panamá e Venezuela. A ausēncia de perspectiva ética pode estar sendo encontrada em muitas campanhas publicitárias veiculadas de inúmeras formas, nos anúncios de produtos, serviços e idéias.

ABSTRACT: The objective of this article is to understand the perception of the ethics concept, the ethical performance and the social responsibility of advertising in Latin America. Definitions of standards and guidelines are presented to allow the comprehension of the advertisers' practices. Trends are analysed in nine countries: Argentina, Brazil, Chile, Costa Rica, Guatemala, Honduras, Mexico, Panama and Venezuela. An ethical perspective might be missing in some advertising campaigns for products, services and ideas.

PALAVRAS-CHAVE: ética, atividade de propaganda, responsabilidade social, América Latina.

KFY WORDS: ethics, advertising campaigs, social responsibility, Latin America. 
1. CHESKIN, Louis. Por que se compra. São Paulo: Pioneira, 1964.

2. CHILDS, Marquis W., CATER, Douglas. A ética em uma sociedade mercantil. São Paulo: Civilização Brasileira, 1957; FERRELL, O. C., WEAVER, Mark $\mathrm{K}$. Ethical beliefs of marketing managers. Journal of Marketing, v. 42 , p. $69-73$, July 1978 ; SÁFADY, Naief. Publicidade e propaganda. Rio de Janeiro: FGV, 1973.

3. ARRUDA, Maria Cecilia Coutinho de. Ética: uma preocupação emergente no campo do marketing social. Marketing, São Paulo, n. 151 , p. 29-38, maio 1986.

4. MALANGA, Eugênio. Publicidade: uma introdução. São Paulo: Atlas, 1976; PORRAS, J. I., WEINBERG C. P.A framework for analysing the ethics of marketing interventions. In: Government marketing: theory and tractice. New York: Steven E. Permut, 1981.

5. ARRUDA, Maria Cecilia Coutinho de. Ética na administração de marketing: um estudo exploratório no campo da comunicacão e conceito de produtos, serviços e idéias. São Paulo: Faculdade de Economia e Administração/Universidade de São Paulo, 1986. (Tese de doutorado)

6. LUCK, David J. Broadening the concept of marketing - too far. Journal of Marketing, v. 33, n. 3 , p. 53-5, July 1969 .

7. ROBIN, D. P. Value issues in marketing. In: LAMB Jr., C. W., DUNNE, P. M. (orgs.). Proceedings series: theoretical developments in marketing. American Marketing Association, 1980.
Há muito tempo se comenta que um comportamento ético dos publicitários ou dirigentes de agências de propaganda é dificilmente praticáve ${ }^{1}$, em face dos problemas enfrentados pela sociedade atual, pelas empresas privadas, pelas agências de pesquisa e publicidade, pelos veículos de comunicação, pelos governos ${ }^{2}$. Em muitos países ocidentais observam-se conflitos entre os valores éticos ou morais e os do sistema econômico-social, e muitos profissionais se vêem desnorteados com respeito à atitude correta a ser tomada em face das dinâmicas e diversificadas possibilidades com que se deparam, ao formular suas campanhas publicitárias ${ }^{3}$.

O propósito deste artigo é despertar a atenção dos acadêmicos e, mais especificamente, dos profissionais que lidam com propaganda para a responsabilidade que assumem em relação ao mercado em que operam, incentivando-os a ponderar sobre os valores implícitos nas campanhas que desenvolvem. Tal postura pode orientá-los para o bem comum, levandoos a uma atuação sábia e prudente.

Tendo em vista a liberdade de que é dotado, por natureza, o ser humano, os códigos de ética, embora necessários para todas as carreiras, parecem não ser suficientes por si sós para orientar um publicitário na totalidade das circunstâncias e áreas com que se defronta. É imprescindível que ele domine o conhecimento de princípios básicos de ética sobre a natureza humana e sobre a vida comercial, constantemente refletindo sobre eles. Desta forma, reduzir-se-ão grandes incertezas na seleção de alternativas e serão discernidas com propriedade as decisões a seguir nos negócios ${ }^{4}$.

Entende-se que uma personalidade harmoniosa só se desenvolverá se estiver lastreada numa ideologia realista, e isso exige estudo, aprofundamento. Muitos acadêmicos e profissionais trabalham hoje com seriedade e competência, exigindo de si mesmos rigor científico e um estudo o mais objetivo possível. Ao mesmo tempo, porém, entendem a objetividade como a resultante de uma média estatística de todas as opiniões, e não parecem interessados em conhecer a verdade. Esta atitude reflete uma mentalidade, muito difundi- da na universidade e no mundo empresarial, de que a ciência e a técnica seriam totalmente estranhas às verdades últimas referentes ao homem e à sua vida, servindo apenas de instrumentos de qualificação profissional. Ao contrário do que se crê que deveria ser, o estudo e o trabalho não chegam a afetar a pessoa de um modo mais profundo, de modo que ela deixa de se formar em suas facetas mais importantes e decisivas. Dentro de uma abordagem filosófica realista, a inteligência deve dirigir-se à verdade para não se deixar levar

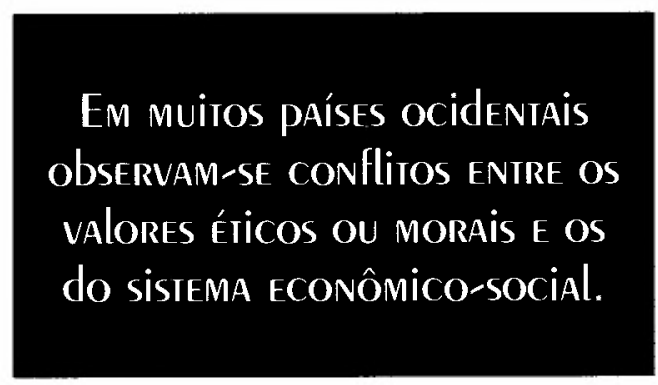

por vieses do relativismo; a vontade deve encaminhar-se ao bem; o homem, assim, com sua personalidade completa, chegará à objetividade dos valores, sem sucumbir a qualquer forma de subjetivismo ${ }^{5}$.

Em face da frivolidade ${ }^{6}$ que permeia muitos ambientes onde se desenvolve a atividade publicitária, profissionais desta área já se propuseram a elaborar códigos de ética específicos para nortear seu comportamento. No entanto, por assumir o relativismo filosófico como base de seus conceitos fundamentais, não conseguiram atingir um consenso em um mínimo de princípios necessários ${ }^{7}$. O fato de que na maior parte das universidades norte-americanas, hoje, predomina a linha de pensamento do relativismo ético não significa que ela seja verdadeira nem, muito menos, a única. Aliás, ao contrário, sempre que o ponto de partida para a solução moral de um dilema não é a realidade, fica impossível estabelecer o que é reto e correto, pois cada indivíduo se deixa reger por um sistema de valores próprio, e nada ou pouco de objetivo resta à análise. Explicase, dessa forma, a grande inquietação manifestada, desde há muito tempo e com freqüência, pelos autores norte-america- 
Tabela 1 - Composição da amostra

\begin{tabular}{|l|l|l|}
\hline Países & $N^{2}$ de publicitários selecionados & $N^{2}$ de publicitários que participaram \\
\hline Argentina & 10 & 2 \\
\hline Brasil & 139 & 16 \\
\hline Chile & 10 & 2 \\
\hline Costa Rica & 4 & 1 \\
\hline Guatemala & 5 & 1 \\
\hline Honduras & 1 & 1 \\
\hline México & 10 & 1 \\
\hline Panamá & 2 & 1 \\
\hline Venezuela & 10 & 2 \\
\hline Total & 191 & 27 \\
\hline$\%$ & 100,0 & 14,1 \\
\hline
\end{tabular}

nos, bem como sua impossibilidade de equacionamento do problema ético.

$\mathrm{Na}$ América Latina, onde predomina o humanismo judaico-cristão, entende-se que a compreensão de conceitos éticos da filosofia realista deveria ocorrer de maneira mais positiva e intensa do que em outras regiões do globo.

Considerando esta realidade, buscou-se mediante um estudo empírico avaliar quão próximos os publicitários se encontram da lei natural e de outros princípios morais fundamentais.

\section{A PESQUISA}

O estudo em tela, de caráter exploratório, procurou apreender entre profissionais publicitários sua percepção sobre o conceito de ética, sua performance ética e responsabilidade social na atividade de propaganda, os padrões e diretrizes que norteiam sua açāo. Objetivou-se, assim, identificar tendências passíveis de verificação ulterior em estudos dotados de maior rigor metodológico.

De acordo com a metodologia adotada, pode ser classificado como um típico estudo de campo, em que às opiniões, atitudes e valores pesquisados foram atribuídas medidas aproximadas e indiretas. Portanto, ressalte-se que há uma série de limitaçōes no poder de inferência dos resultados obtidos.

A partir de um conhecimento já acumulado sobre as agências de propaganda, constituiu-se uma amostra intencional de 191 profissionais representando nove países. Desses profissionais, contatados no período de julho a outubro de 1994, apenas $27(14,1 \%)$ participaram efetivamente da pesquisa. Esse baixo índice de participação deveu-se, em boa medida, ao próprio procedimento de coleta de dados. Foram enviadas por correio duas remessas de questionários a dirigentes ou proprietários de agências de publicidade no Brasil e em oito países da América Latina: Argentina, Chile, Costa Rica, Guatemala, Honduras, México, Panamá e Venezuela. O percentual de devoluções do material pelo correio foi elevado, em funçāo de muitas mudanças de endereço.

$O$ índice de omissões também foi grande, embora esperado. A explicação mais razoável para tal fato deve-se a dois fatores principais: o constrangimento ao responder um questionário identificado, sobre temas morais, ainda que se garantisse a confidencialidade no tratamento e divulgação dos dados, e a extensão do questionário (170 assertivas, sendo que apenas as 28 primeiras constituem aqui objeto de análise), bastante longa para um dirigente de agência, geralmente um profissional que trabalha sob forte pressão de tempo. Alguns manifestaram desconforto em responder a um questionário em que se indagavam tópicos com os quais não lidam habitualmente: questões relativas ao conceito de ética. Essa dificuldade, já esperada, foi avaliada, pois constituía um dos pressupostos da pesquisa o desconhecimento dos publicitários ou proprietários de agências de propaganda a respeito de princípios filosóficos. A tabela 1 detalha a composição da amostra pesquisada e os países dos respondentes.
8. Idem, ibidem. 
Para atualizaçāo das informaçôes coletadas, e aprofundamento na compreensão das mesmas, foram mantidos contatos com profissionais trabalhando em projetos de especial interesse para a pesquisa, no Brasil e no exterior. A confecção do questionário apoiou-se nas definições ou conceitos que constam do quadro 1.

As várias discussões empreendidas na literatura acerca da ética levaram a definir um processo de mensuração baseado nas noçôes de comportamento atual (o que os publicitários ou dirigentes de agências de publicidade afirmam) e ideal (de acordo com os parâmetros éticos definidos). $O$ s índices foram obtidos a partir do grau de concordância apontado para cada uma das alternativas. Para chegar a esses índices foi definida uma escala de cinco pontos que procurou refletir a opinião dos respondentes: " 1 " significou máxima discordância, e " 5 " a máxima concordância. Assim, em cada dimensão a percepção foi expressa por uma escala que variou de " 0 " a " 4 ".

Os publicitários ou dirigentes de agências de propaganda foram convidados a responder com a máxima franqueza possível, seguindo as instruções impressas em cada questionário, e os que o fizeram não necessitaram de qualquer intervenção dos pesquisadores.

\section{Análise e interpretação dos dados}

A figura 1 mostra a distribuição dos dados relativos à percepçāo do conceito de ética coletados entre os 27 informantes. Nela, confrontam-se, a partir da mediana das respostas obtidas em cada dimensão, os comportamentos atual (linha cheia) aquele representado pelas respostas efetivas ao questionário - e ideal (linha mais fina) - aquele que se esperava que fosse manifestado de acordo com a filosofia realista.

Na figura 2, diferenciam-se os dados relativos ao Brasil (linha mais fina) e ao consolidado dos países hispânicos: Argentina, Chile, Costa Rica, Guatemala, Honduras, México, Panamá e Venezuela (linha cheia). A diferente formação histórica destes dois grupos pode ter exercido influência sobre as respectivas percepções do conceito de ética, razão pela qual

Quadro 1 - Definiçōes e conceitos relativos à ética

\begin{tabular}{|c|c|}
\hline I. & $\begin{array}{l}\text { Ética: parte da filosofia que estuda a moralidade do agir humatıo, quer dizer: considefa os alos humatios } \\
\text { enquanto bons ou maus. }\end{array}$ \\
\hline 2. & Lei: ordenação prática da conduta humana, estabelecida por uma autoridade competejte. \\
\hline 3. & $\begin{array}{l}\text { Lei hamana: reto ditame da racăo. en ordern ao bem comum. promulgado por aquele que tem função de } \\
\text { governo na comunidade, pela autoridade. }\end{array}$ \\
\hline 4. & Verdade: capacidade que as coisas têm de ser entendidas por uma inteligência, no que realmente são. \\
\hline 5. & $\begin{array}{l}\text { Fim último: fim absoluto que preenche toda capacidade de desejar. conhecer e amar do homem; é aquele } \\
\text { bem que se deseja, busca ou apetece de tal maneira que năo se refere a uenhum outro (totalidade). }\end{array}$ \\
\hline 6. & Fim: o bem pelo qual se taz algo. \\
\hline 7. & Conteudo da moral natural: ordenação do ato humano ao seu fin último. \\
\hline 8. & $\begin{array}{l}\text { Consciência: juizo concomitante moral que detemina a moralidade das açòes; pode ser reta, certa, } \\
\text { duvidosa, laxa, escrupulosa. }\end{array}$ \\
\hline 9. & Obstáculos ao fun últino: malicia, ignoråncia e debilidade. \\
\hline 10. & $\begin{array}{l}\text { Liberdade: atuação por aquilo que verdadeiramente conduz o homem ao sen aperfeiçoamento conı ser } \\
\text { humano, ou seja. querer o ben. }\end{array}$ \\
\hline 1.1. & $\begin{array}{l}\text { Fins existenciais: a própria conservação: a propria perfeição, fisica e espiritual; ampliação da experiçucia. } \\
\text { do saber, da capacidade de apreciação da beleza: reproduça e educação dos filhos: união social para } \\
\text { estimular o bem geral; participação no bem-estar material e espiritual dos homens; conlhecimento e culto a } \\
\text { Deus. }\end{array}$ \\
\hline 12. & Ideologias: concepções sobre a natureza e finalidade do homem e da sociedade. \\
\hline 13. & Fatores inportantes no sistema social: idéias, usos e costumes. \\
\hline 14. & Questăo social: uma enfermidade ou quebra no corpú social. \\
\hline 15. & Natureza social do homent tendência à vida social para alcançar seus fins. \\
\hline 16. & $\begin{array}{l}\text { Sociedade: união moral estável, sob uma única autoridade, de várias pessoas. lissicas ou morais. gue } \\
\text { tendem ao bem comum. }\end{array}$ \\
\hline 17. & Ordem social: unidade social. \\
\hline 18. & $\begin{array}{l}\text { Bem comum como fim e funçăo da sociedadc: para que cada individuo alcance os fins cxistenciais: fim } \\
\text { ùltimo da sociedade é inportante para organizações e mudanças na ordem social; definição e } \\
\text { planejamento do bem comum depende da vontade e arbítrio da sociedade. denuro dos limites da ordem } \\
\text { natural e ordenação dos fins existenciais. }\end{array}$ \\
\hline 19. & Ordem: profissões e instituiçōes buuanas: contribuir para o bem (virtudes). \\
\hline
\end{tabular}


Figura 1 - Conceito de ética: comportamento ideal versus atual

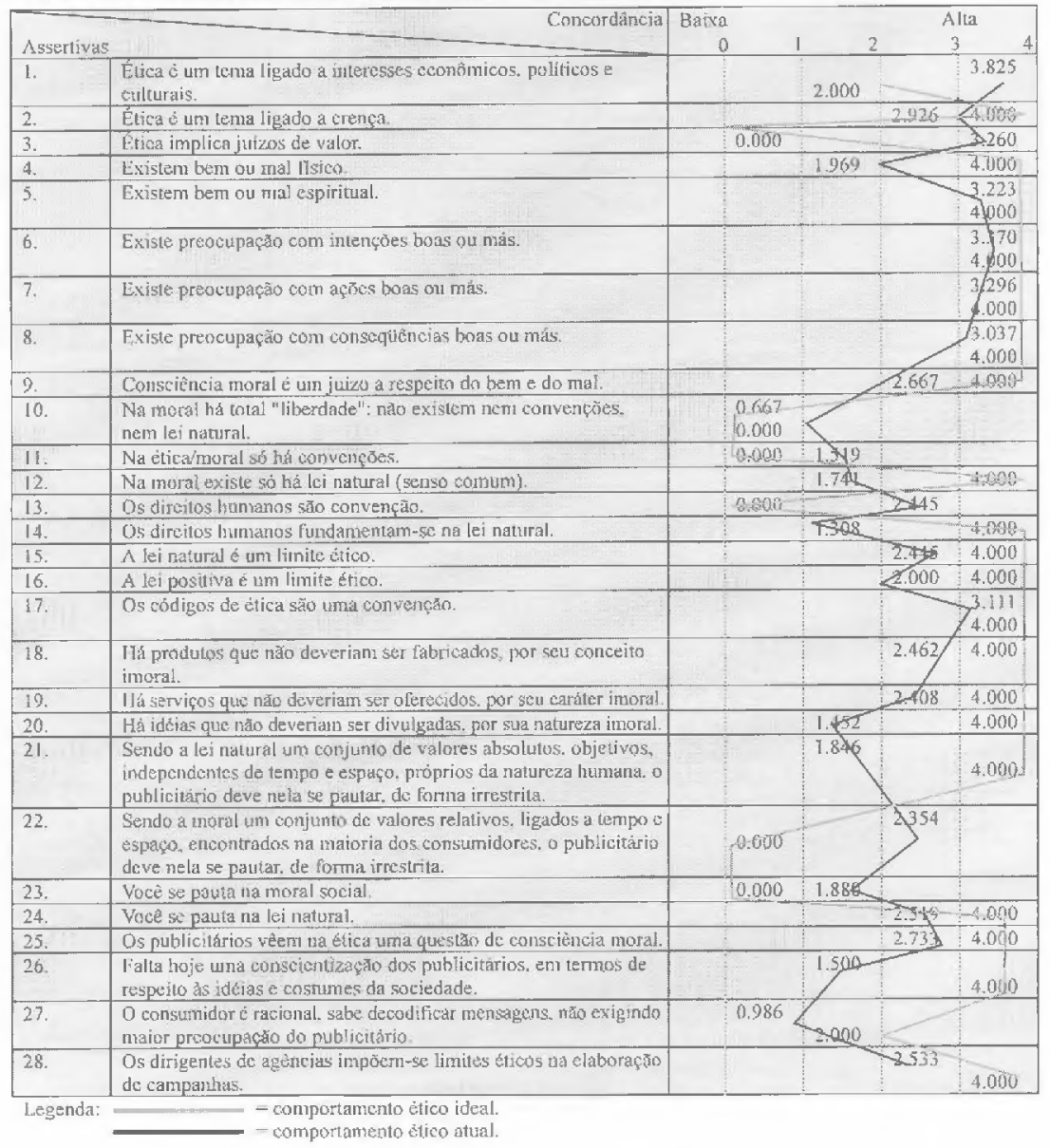

se procurou analisar suas medianas em separado.

De acordo com a figura 1, é possível notar, no ponto de vista dos publicitários, uma discrepância entre o conceito de ética enquanto juízo de valor e enquanto lei natural (3.260 contra zero). Esse pode ser um indicador da filosofia relativista que parece predominar no ambiente publicitário do Brasil e da América Latina como uin todo.

Pela figura 2, verifica-se maior preocupação quanto a ações e consequiências boas ou más entre os publicitários brasileiros (acima de 3.000) do que entre os dos demais países analisados. Por outro lado, no que tange à consciência moral enquanto juízo a respeito do bem e do mal, os brasileiros se mostraram muito afastados do conceito correto. Considerando-se que nos países hispânicos a religiosidade da populaçāo é geralmente mais acentuada, podese supor que o conceito de consciência seja, por isso, mais bem compreendido (3.545, contra 2.063 entre os brasileiros).

Observou-se um ponto de distanciamento nas respostas de todos os países quanto à existência de bem ou mal físico (1.969 contra 4.000, figura 1). Segundo a tendência apontada na figura 2 , Chile e Venezuela influenciam esta disparidade. Uma doença, um defeito ou uma limitação são exemplos de males físicos que não necessariamente implicam males morais. A condiçāo de criaturas corpóreas, por si, indica a inclinação ao mal, por" sua perecibilidade.

Duas questōes relativas à lei natural parecem mostrar reduzido conhecimento da filosofia realista em todos os países da pesquisa. Com base na figura 1, não assumir a lei natural como único princípio moral (1.741 contra 4.000) parece implicar o erro conceitual de julgar que nāo existe uma lei natural moral a reger os seres livres, ou seja, os humanos. Por essa razāo, 
Figura 2 - Conceito de ética: Brasil versus demals paises da América Latina

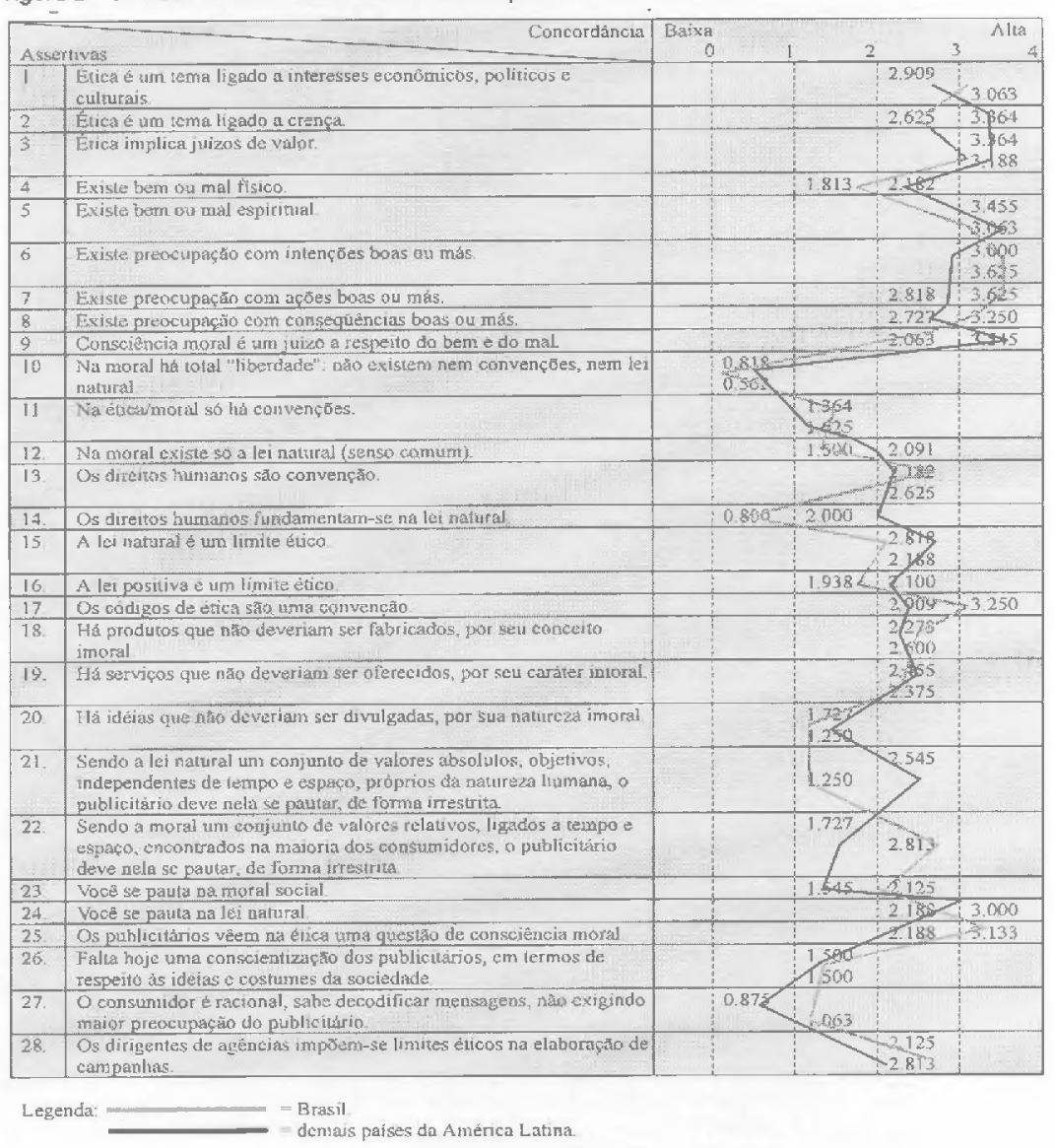

também a lei natural não foi percebida como fundamento dos direitos humanos (1.308 contra 4.000$)$, sendo atribuído a estes o caráter de convençāo (2.445 contra zero). Este distanciamento da realidade parece indicar a moral social como fonte de moralidade, o que pode levar a sérios vieses éticos.

O relativismo filosófico parece impedir a visāo dos respondentes sobre a moralidade implícita em produtos, serviços e idéias $(2.462,2.408$ e 1.452 , respectivamente, contra 4.000 , figura 1). As respostas oriundas do Brasil se mostraram mais próximas da objetividade característica da lei natural (2.545 contra 1.250, figura 2). Esta mesma tendência se observa na figura 1, quando muito poucos publicitários se pautam de forma irrestrita na lei natural (1.846 contra 4.000), entendendo ser a moral um conjunto de valores relativos, ligados a tempo e espaço, encontrados na maioria dos consumidores (2.354 contra zero). Esta visão foi especialmente apontada pelos panamenhos.

\section{CONCLUSŌES}

A pesquisa realizada aponta tendência de que esteja havendo ausência de perspectiva ética em muitas campanhas publicitárias veiculadas de inúmeras formas, nos anúncios de produtos, serviços e idéias. $\mathrm{O}$ aparente desnorteamento dos publicitários brasileiros, assim como dos demais países latino-americanos, parece indicar desinteresse e/ou desinformação a respeito da experiência profissional em muitas nações onde, pelos resultados nada satisfatórios, algumas práticas nāo-éticas já foram, há tempos, abandonadas.

Faz-se imperiosa a necessidade de complementar a formação ética de estudantes de propaganda e marketing, administradores, publicitários, pesquisadores e mesmo de professores, para que se introduza o hábito de raciocínio dentro de limites éticos, garantindo mais liberdade de ação e maior responsabilidade social.

Os limites éticos, hoje, parecem restringir-se aos códigos de ética, à legislaçāo vigente no país e, quando muito, aos há- 
bitos e costumes detectados por pesquisa ou por sensibilidade. Pouca ou nenhuma atenção tem sido dada à lei natural, aos valores e crenças das pessoas, especialmente quando se trata do mercado consumidor. Os direitos humanos, expressos na respectiva Declaração Universal de 1948, que refletem o direito natural, são apenas parcialmente lembrados. Se a lei natural fosse tomada por base para a definição dos limites éticos, muitas campanhas de produtos, serviços e idéias deixariam de existir.
Entende-se que os usos sociais influem sobre o comportamento humano, já que refletem e condicionam o sistema de valores de uma sociedade. A morálidade desses usos e meios corresponde à dignidade da natureza humana e social, justificando que se estude a forma de sensibilizar a classe publicitária e os demais profissionais de marketing, em todo o mundo, para a grave responsabilidade que assumem diante de sua aparente alienação dos deveres e obrigações éticas para com os cidadãos.

\section{BIBLIOGRAFIA COMPLEMENTAR}

BARTELS, Robert. A model for ethics in marketing. Journal of Marketing, v. 31, p. 20-6, Jan. 1967.

BAUMHART, Raymond C. How ethical are businessmen? Harvard Business Review, Boston, v. 39, p. 6-19, 156-76, Jul./Aug. 1961.

BENET, Suzeanne, PITTS, Roberto E., LA TOUR, Michael. The appropriateness of fear appeal use for healthcare marketing to the elderly: is it $0 \mathrm{~K}$ to scare grammy? Journal of Business Ethics. v. 12, n. 1, p. 45-55, Jan. 1993.

BODDEWYN, Jean J. Advertising self-regulation and outside participation: a multinational comparison. Westport, Conn.: Quorum, 1988.

BODDEWYN, Jean J. Decoro e sexismo em publicidade. Painel: Ética e legisiação. Simpósio Internacional de Publicidade. São Paulo, Nov. 1983

CONAR. Inter-American Economic Affairs, v. 38, n. 3, 1984

BRENNER, Steven N., MOLANDER, Earl A. Is the ethics of business changing? Harvard Business Review, Boston, v. 55, p. 57-71, Jan./Feb. 1961.

BREWER, Geoffrey. Be like Nike? Sales \& Marketing Management, v. 145, n. 11, p. 66-74, Sept. 1993.

CHOZA, J. La supresión del pudor. Nuestro Tiempo, n. 205, p. 11-2, Jul. 1971.

Código de Auto-Regulamentação Publicitária - São Paulo: CONAR, 1985.

CONAR, de olho na propaganda. O Estado de S. Paulo - Caderno de Empresas, São Paulo, 15 ago. 1985, p. 3.

CORRÊA, Petrônio. A liberdade de anunciar. São Paulo: CONAR, 1982.

COUGHLIN, Dan. Tobacco money llght up Congress. Business \& Society Review. n. 83, p. 19-21, Fall 1992.

DAVIS, Joel J. Good ethics is good for business: ethical attributions and response to environmental advertising, Journal of Business Ethics, v. 13, n. 11, p. 873-886, Nov. 1994.

Defesa do Consumidor. Superhiper, Set 1981, p. 62

DUKE, Charles R. et al. A method for evaluating the ethics of fear appeals. Journal of Public Policy \& Marketing, v. 12, n. 1, p. 120-9, Spring 1993.

Estatuto da ABAP - Associação Brasileira de Agências de Propaganda.

Estatutos Sociais do Conselho Nacional de Auto-Regulamentação Publicitária. CONAR. 1985. p. 22

ETHICS RESOURCE CENTER. Codes of ethics in corporations and trade associations and the teaching of ethics in graduate business schools. Princeton, New York:

Opinion Corporation, 1979

FERRELL, James M., GRESHAM, Larry G. A contingency framework for understanding ethical decision making in marketing. Journal of Marketing, v. 39 , p. 87 ,

Summer 1985.

GER - GRAN ENCICLOPEDIA RIALP. Madrid: Rialp, 1979, t. IX. p. 497.

GOERNE, Carrie. Pharmaceutical companies compete agressively to help smokers quit habit. Marketing News, v. 26, n. 7, p. 8-11, 30./Mar/92.

GREEN, Michael K. Images of native Americans in advertising: some moral issues. Journal of Business Ethics, v. 12, n. 4, p. 323-30, Apr. 1993.

GRIFFIN, George. Advertising's greatest challenge. Graphic Arts Monthly, v. 65, n. 11, p. 92-4, Nov 1993.

HIGHAM, Nick. The moral of the story. Marketing Week, v. 16, n. 37, p. 19, Nov. 1993.

IF THE Vatican calls. Advertising Age, Chicago, v. 64, n. 38, p. 26, 13 Sept. 1993.

ISAACS, David. La educación de las virtudes humanas. 4 ed. La educación del pudor. Pamplona: Universidad de Navarra, tomo I, 1980. p. 233.

JAFFE, Andrew. Advertiser, regulate thyself. Adweek, v. 34, n. 31, p. 38, Aug. 1993.

JOLIVET, Régis. Curso de Filosofia. 6. ed. Rio de Janeiro: Agir, 1963. p. 448.

KIERNAN, Penny. First salvos fired in the phoney ad war. Marketing Week, v. 16, n. 32, p. 23, 0ct. 1993

LACZNIAK, Gene R. Business ethics: a manager's primer. Business, v. 33, p. 23-9, Jan./Mar. 1983.

MARTIN, Michele. No nipples on our screen please, we're British. Campaign-London, 15/Jul/94. p. 13.

MURPHY, Patrick, LACZNIAK, Gene R. Marketing ethics: a review with implications for managers, educators and researchers, In: Review of Marketing, 1981. ENNIS,

Ben M., ROERING, Kenneth J.(eds) Chicago: American Marketing Association. p. 251-66.

NUNES, Ruy. Inteligência e estudo da Filosofla. O Estado de S. Paulo, São Paulo, 20 jun. 1986, p. 2.

PATTERSON, James M. What are the social and ethical responsibilities of marketing executives? Journal of Marketing, v. 3, p. 12-5, Jul. 1966.

PETERSON, Robin T. The depiction of senior citizens in magazine advertisement: a content analysis. Journal of Business Ethics, v. 11, n. 9, p. 701-6, Sept. 1992

PLANT, Fiona. Comparative ads make contentious come-back. Campaign-London. 15 Oct. 1993, p. 16.

POMEROY, Henry J. et al. Distilling the truth about alcohol ads. Business \& Society Review, n. 83, p. 12-7, Fall 1992.

PROPAGANDA brasileira já é a sexta do mundo. Diário Comércio e Indústria, São Paulo, 26 jan. 1986.

Ranking das agências de propaganda - 1984. FENAPRO.

RODRIGUEZ LUNNO, Angel. Etica. Pamplona: Universidad de Navarra, 1982. p. 93.

ROTFELD, Herbert, LACHER, Kathleen. Advertisers have little say on news coverage. Marketing News, v. 28, n. 1, p. 4-5, Jan. 1994.

SILVA, Maria de Lourdes Seraphico Peixoto da. 0 direito de não ver. O Estado de S. Paulo, São Paulo, 5 nov. 1985. p. 44.

SNYDER, Wally. Advertising's ethical \& economic imperative. American Advertising, v. 9, n. 3, p. 28, Fall 1993.

THACKER, Kathy. Brassy vs. classy creative: defining taste in advertising. Adweek. v. 15, n. 12, p. 46, Mar. 1993.

TYBOUT, Alice M., ZALTMAN, Gerald. Ethics in marketing research: their practical relevance. Journal of Marketing Research, v. XI, p. 357-68, Nov. 1974.

VAN WENSVEEN SIKER, Louke, DONAHUE, James A., GREEN, Ronald M. Does your religion make a difference in your business ethic? The case of consolidated food. Journal of Business Ethics, v. 10, n. 11, p. 819-32. Nov. 1991. 